\title{
VIRTUAL MODELING FOR CITIES OF THE FUTURE. STATE-OF-THE ART AND FUTURE CHALLENGES.
}

\author{
J. Valencia ${ }^{\mathrm{a}, *}$, A. Muñoz-Nieto ${ }^{\mathrm{b}}$, P. Rodriguez-Gonzalvez ${ }^{\mathrm{b}}$ \\ ${ }^{a} \mathrm{PhD}$ candidate Department of Cartographic and Land Engineering; High School of Ávila, University of Salamanca, Ávila, Spain - \\ javi.valencia.m@gmail.com \\ ${ }^{\mathrm{b}}$ Department of Cartographic and Land Engineering; High School of Ávila, University of Salamanca, Ávila, Spain - \\ (almuni, pablorgsf)@usal.es
}

Commission V, WG V/4

KEY WORDS: Cartography, Rendering, City, Three-dimensional, Spatial Infrastructures, Visualization, GIS, Virtual Reality

\begin{abstract}
:
3D virtual modeling, visualization, dissemination and management of urban areas is one of the most exciting challenges that must face geomatics in the coming years. This paper aims to review, compare and analyze the new technologies, policies and software tools that are in progress to manage urban 3D information. It is assumed that the third dimension increases the quality of the model provided, allowing new approaches to urban planning, conservation and management of architectural and archaeological areas.

Despite the fact that displaying 3D urban environments is an issue nowadays solved, there are some challenges to be faced by geomatics in the coming future. Displaying georeferenced linked information would be considered the first challenge. Another challenge to face is to improve the technical requirements if this georeferenced information must be shown in real time. Are there available software tools ready for this challenge? Are they useful to provide services required in smart cities?

Throughout this paper, many practical examples that require 3D georeferenced information and linked data will be shown. Computer advances related to 3D spatial databases and software that are being developed to convert rendering virtual environment to a new enriched environment with linked information will be also analyzed. Finally, different standards that Open Geospatial Consortium has assumed and developed regarding the three-dimensional geographic information will be reviewed. Particular emphasis will be devoted on KML, LandXML, CityGML and the new IndoorGML.
\end{abstract}

\section{INTRODUCTION}

Three-dimensional rendering of complex architectural environments is nowadays, one of the most attractive challenges in Geomatics.

Advances in geographic information acquisition and development of hardware and software, are opening new perspectives for the management of the third dimension, making possible a new outlook as a result of the ability to include Virtual and Augmented Reality.

Thanks to advances in technologies such as LiDAR, Mapping Mobile Systems (MMS), unmanned aerial vehicles (UAV), etc. (Niemeyer et al., 2014) (Haala et al., 2008) (Puente et al., 2013) (Nex and Remondino, 2014) and linked to the progress of new theories about Big Data, Smart Cities, Building information modeling (BIM), (Volk et al., 2014) etc., a need has been detected to develop new data models able to work with the third dimension and related new 3D features. Also, the temporal component involves an additional challenge, because allows a better understanding of the temporary changes of urban environment. In this sense, they are also necessary databases equipped to cope with these models and software tools for their management and visualization.

Although there are some initiatives emerging to overcome weaknesses in management and publishing three-dimensional geographic information, we can consider that the adaptation of the third dimension is in an initial stage, with many challenges, due to the growth of applications in several fields of engineering and architecture (Yin and Shiode, 2014).

On the one hand we have many tools able to acquire 3D information and, on the other hand, the solutions for rendering and displaying this information are in a point of great maturity. But, what happens when, in addition to display threedimensional environments, we display information associated with them? And what about technical requirements if this georeferenced information should be shown in real time? Are software tools ready for this challenge? Do they have functionality for this kind of services? Through this paper, a review, comparison and analysis of several solutions that have emerged to solve these requirements is carried out.

The paper is structured as follows: In section two we will overview different elements and types of modeling. Section three is devoted to discuss problems associated when modeling cities and other large areas. In section four we will deal with the 3D information publishing and dissemination. Finally the conclusions are given in section five.

\section{3D MODELING OF LARGE AREAS}

\subsection{Overview}

Third spatial dimension has become a real need for many technical and scientific tasks (Scianna and Ammoscato, 2010). Frequently it has been used as an attribute or as additional

\footnotetext{
* Corresponding author.
} 
information attached to geographic features to enable further spatial analysis.

Getting three-dimensional information no longer reflects the technological and financial effort that it used to take few years ago, but today is already possible to obtain significant results with less effort and resources (van Oosterom et al., 2008). From a theoretical point of view, the lack of the third spatial dimension decreases objectively the quality of the cartographic models (Varela García et al., 2007). We should also note the importance of the third spatial dimension from the practical point of view since an increasing number of scientific fields, requires 3D dataset and analysis in order to improve their research i.e. medicine, industrial engineering, urban planning, geology, architecture, etc. (Calle et al., 2010).

Rendering three-dimensional environments is a task well solved by different software tools able to design, create, and model spatial structures, both simple and complex, effortlessly and with a high degree of realism. Basically the starting point is a 3D model, from CAD files or modeling software, and a set of measurements that are added to its features and proprieties. In order to achieve photorealistic effect, textures and lighting models are also applied (Bénitez and Baillard, 2009)

In most cases, the aim of $3 \mathrm{D}$ rendering is to show some infrastructure that already exists and, due to its importance in the study area, worth to be modeled. In other cases, for the infrastructures to be built in the future, the aim is to see how would be their appearance. That is the reason because urban planning, architecture or heritage conservation increasingly demand 3D rendering (Dellepiane et al., 2011). Since modeling large areas, such as cities, countries or even regions is not feasible from the process described above, information coming from Geographical Information Systems (GIS), together with other datasets acquired by LiDAR, radar, photogrammetry, remote sensing, Mobile Mapping, etc. is been used nowadays.

The current problems lie in store and manage all the enormous amount of data. In this sense, a powerful database manager (van Oosterom et al., 2008) is essential. Examples of such situations could be the attempts that several countries are developing in order to achieve 3D cadasters (van Oosterom et al., 2011) is. Another factor of complexity that can be added to the above 3D scenarios is the need to link information with the various elements of our three-dimensional model. Problems related with exchanging data format also must be solved.

\subsection{Modeling cities in 3D}

Three-dimensional city models are already considered as a very important resource for urban planning and for decision-making in urban policies (van Oosterom et al., 2008). Many of them are based, as already mentioned, on information stored in GIS. The simplest but effective modeling strategy is the extrusion of $2 \mathrm{D}$ building shapes getting heights from other sources of information such as LIDAR. These models can be created quickly, providing an easy way to 3D city displaying. This first modeling approach has been used successfully over the Internet, either with browser or plugins developed for this purpose (e.g. Google Earth) (Figure 1), or using webs developed based on OpenGL.

Even though different algorithms are being developed to automate the rendering process is important to highlight that good results with LiDAR point clouds and Poincaré-TEN algorithm have been achieved (Rebecca et al., 2008). However, this modeling strategy has poor capabilities for spatial analysis since it works with two really simple independent datasets. On the one hand the terrain models DTM and on the other hand the building model (DBM).

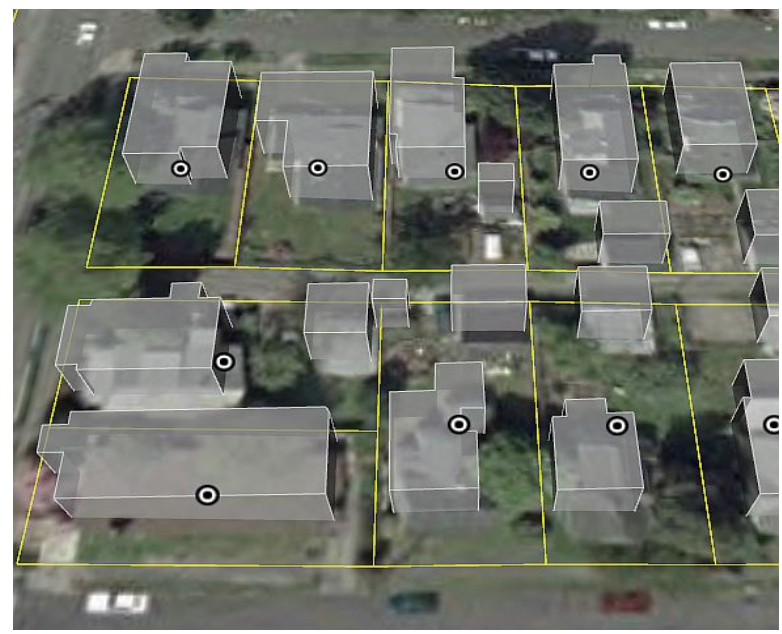

Figure 1. Buildings extruded and uploaded in Google Earth.

This kind of models can be improved by adding information from aerial or terrestrial pictures (Figure 2). In this way, the quality of the model would be higher, since we can get the photographic textures of the buildings. It would be also possible to model and place in their right position the street furniture. Thus we are getting valuable information for spatial analysis of traffic zones or pedestrian areas (Slingsby and Raper, 2008).

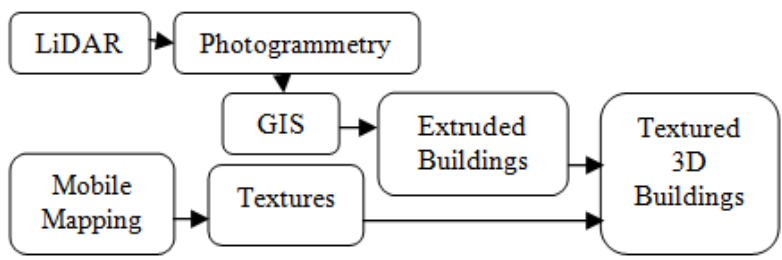

Figure 2. 3D model production workflow.

From these improved models it can be derived a lot of interesting analysis such a 3D topological study of human mobility. Extracting relevant information we can map obstacles for disabled pedestrians. Other possible uses deal with the ability to calculate real distances and routes, both for pedestrian and drivers. Determine urban visual exposure (often used in marketing) will be also possible (Suleiman et al., 2011).

Currently there are different software tools to create and manage these models such as CityEngine, ESRI, Infrastructure Design Suite, Autodesk, Bentley Map, Bentley and GeoMedia 3D Hexagon Geospatial. They have in common a set of options that make them very versatile for generating such models (Figure 3). Uploading information to the city area (DTM, BIM, CAD, 3D models, etc.) is the first step that will be completed with the other elements that make up the model (street furniture and vegetation). Finally aesthetic elements related to the lighting and atmosphere are incorporated (Engel et al., 2012). Although a comprehensive modeling is a high time consuming task, once the city model is created, it becomes very important 
due to their capability to interact with other3D geographic information.

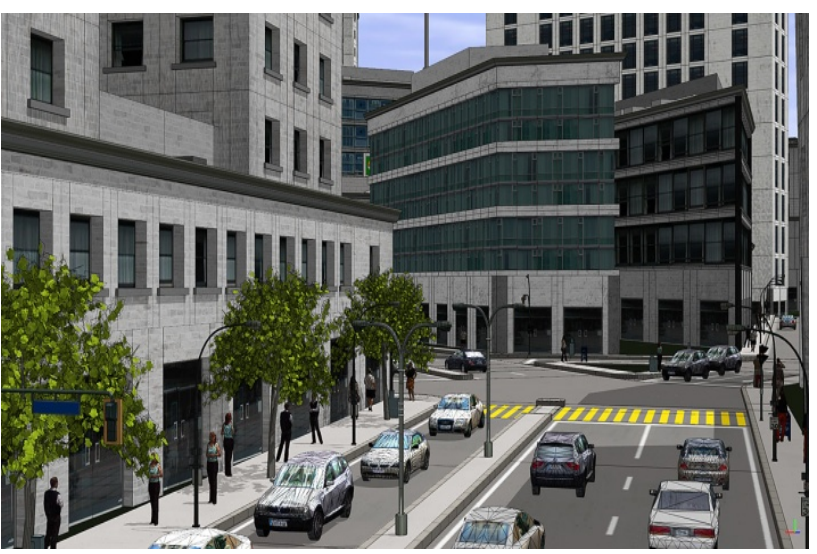

Figure 3. 3D model made with Esri CityEngine. Figure courtesy of Esri.

As seen in the following table (Table 1) not all the software options are equal efficient for related functionalities.

\begin{tabular}{|c|c|c|c|c|}
\hline Functionality & 氞 & 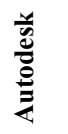 & 冚 & 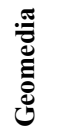 \\
\hline Import CAD and GIS & $\bullet \bullet \bullet$ & $\bullet \bullet \bullet$ & $\bullet \bullet \bullet$ & $\bullet \bullet$ \\
\hline Support Geo DBMS & $\bullet \bullet \bullet$ & $\bullet \bullet \bullet$ & $\bullet \bullet \bullet$ & $\bullet \bullet \bullet$ \\
\hline Editing tools & $\bullet \bullet$ & $\bullet \bullet \bullet$ & $\bullet \bullet \bullet$ & $\bullet \bullet$ \\
\hline 3D Modeling \& Texturing Tools & $\bullet \bullet \bullet$ & $\bullet \bullet \bullet$ & $\bullet \bullet$ & $\bullet \bullet \bullet$ \\
\hline Terrain and Maps & $\bullet \bullet \bullet$ & $\bullet \bullet \bullet$ & $\bullet \bullet \bullet$ & $\bullet \bullet \bullet$ \\
\hline Basic 2D and 3D Format Support & $\bullet \bullet \bullet$ & $\bullet \bullet$ & $\bullet \bullet$ & $\bullet \bullet \bullet$ \\
\hline OpenStreetMap Import & $\bullet \bullet \bullet$ & $\circ$ & 0 & 0 \\
\hline 3D Web Scene & $\bullet \bullet \bullet$ & $\circ$ & $\circ$ & $\circ$ \\
\hline KML Support & $\bullet \bullet \bullet$ & $\bullet \bullet \bullet$ & $\bullet \bullet \bullet$ & $\bullet \bullet \bullet$ \\
\hline CityGML Suport & $\bullet \bullet \bullet$ & $\bullet \bullet \bullet$ & $\bullet \bullet$ & $\bullet \bullet$ \\
\hline 3D Libraries & $\bullet \bullet \bullet$ & $\bullet \bullet \bullet$ & $\bullet \bullet \bullet$ & $\bullet$ \\
\hline Advanced 3D Format Support & $\bullet \bullet$ & $\bullet \bullet \bullet$ & $\bullet \bullet$ & $\circ$ \\
\hline 3D Analysis & 0 & $\bullet \bullet$ & $\bullet$ & $\bullet \bullet \bullet$ \\
\hline 3D Navigation & $\bullet \bullet \bullet$ & $\bullet \bullet$ & $\bullet \bullet \bullet$ & $\bullet \bullet \bullet$ \\
\hline BIM interaction & $\bullet$ & $\bullet \bullet \bullet$ & $\bullet \bullet \bullet$ & $\bullet$ \\
\hline Virtual flights films & $\bullet \bullet$ & $\bullet \bullet$ & $\bullet$ & $\bullet \bullet$ \\
\hline Scripting Interface & $\bullet \bullet \bullet$ & $\bullet \bullet$ & $\bullet$ & $\bullet$ \\
\hline Simulation & $\bullet \bullet \bullet$ & $\bullet \bullet \bullet$ & $\bullet \bullet$ & $\bullet \bullet$ \\
\hline
\end{tabular}

Table 1. Qualitative comparison of software functionality

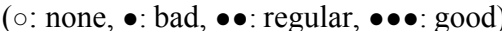

As seen in previous comparative, CAD and GIS tend to converge in many functionalities. However, everything related to the interaction with BIM formats or other advanced 3D formats are best handled in the software that comes from CAD world. Something similar occurs with advanced editing of models. Meanwhile, GIS-derived software has better rendering performance, resulting in much lower resources consumption than the derived CAD software. As a consequence, we can conclude that geomatics and BIM disciplines are converging at the moment (Curtis, 2008), since BIM provides answers to the problem of building modeling and geomatics science, with a multidisciplinary geospatial scope, supply these issues.

Similar tools, currently developed, as RCP (VirtuelCity, 2010) or DbMAP Flyer 3D (GeoMind, 2013) show a worse interaction among various sources of geographical information offering a smaller amount of possibilities for information import. But, it should be taken into account, that since the software complexity and functionalities are reduced, the final city model time also decreases with consequently poor results.

Finally, we have to consider that mention software tools are desktop based, but there are also a cloud based tools option for users. An example of this tools is 5D Smart City (Cityzenith, 2013), which is focused on the creation and management of geospatial components for smart cities (Figure 4).

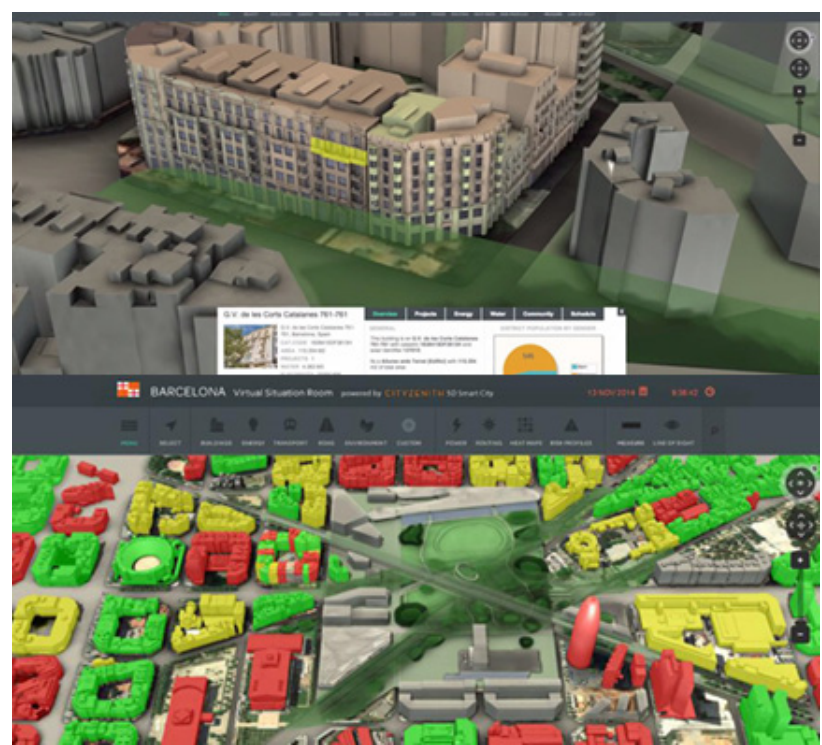

Figure 4. 3D model of Barcelona by 5D Smart City. Figure courtesy of 5D Smart City.

\subsection{Modeling large areas in 3D}

Three-dimensional modeling of large areas (countries, regions, states) implies additional problems. The main one is the amount of information to process, not only for their analysis and management, but also for their possible dissemination or publication on the Web (Elberink et al., 2012). This scenario is undoubtedly one of the main challenges to be addressed by Spatial Data Infrastructures (SDI). SDI have been one of the main drivers of the technological development in geomatics in recent years, but until now they have not a comprehensive answer to the problem of three-dimensionality (Basanow et al, 2008).

The large amount of information to process involves dealing with algorithms, software, analysis and management methods from the Big Data (Amirian et al., 2014). There are two key elements to consider: the data model and the database manager. For to the data model, before addressing this type of problem, a proper definition of the required level of detail is fundamental. As well as, the different guidelines and/or standards provided by the organization and committees (OGC, FGDC, ISO,...). Regarding to the database manager, its capability to deal with the $3 \mathrm{D}$ information is required. In this sense, is worth to mention Oracle and PostGIS developments (Herreruela, 2012) to allow not only storing spatial information, but also associated alphanumeric information, and also performing several topological and geospatial analysis functions (Walenciak et al., 2009).

All advances in the context of SDI and the management of Big Databases, involve linking spatial DBMS with 3D models using Web protocols (Zlatanova et al., 2004). 
In this way many kind of projects can take advantage of this union, such as 3D cadaster (Figure 5), control and monitoring of people in the area of Geospatial Intelligence or the control and management of supply networks.

However, in several of these projects an added problem has to be considered; the online publication of 3D models with associated information.

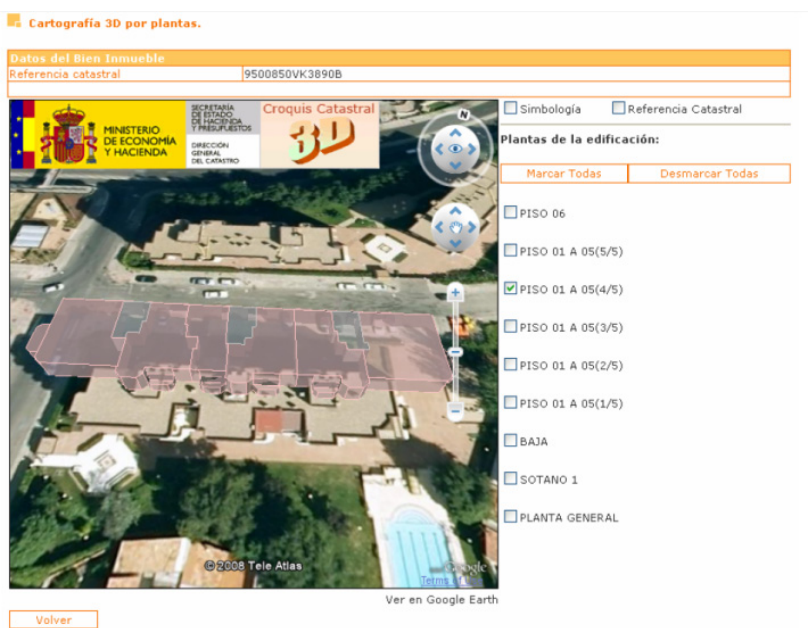

Figure 5. 3D cadastral sketch. Figure courtesy of Luis Ignacio Virgós Soriano and José Miguel Olivares García, General Direction of Cadastre of Spain.

\section{3D MODELING WITH ASSOCIATED INFORMATION}

One of the most complex issues addressed in this paper is threedimensional models with linked alphanumeric information. When a complex 3D model must incorporate alphanumeric data, a new data model is needed. The problem is not to combine the two data models solving storage or management problems, but the increasingly demand to serve or publish these two types of information.

The great diversity of file formats for the 3D information storage, such as, STL, OBJ, DAE, 3DS, DWG, DGN, JSON... is increasing since, virtually, every $3 \mathrm{D}$ modeling software has its own format created to serve a specific goal, in spite the import/export capabilities. However, none of the mention file formats are able in a comprehensive way to incorporate alphanumeric information associated with geometric elements.

The incorporation of alphanumeric information linked with geometric features is essential for the city modeling (Pinto et al., 2013) this way; it is possible move for 2D GIS to 3D GIS, allowing us to address the 3D SDI (Figure 6). The 3DGIS provides, besides the proper methods for geometric representation, the possibility to link semantic information. In this way, the current research lines are focused on filling the gap between the urban simulation and urban space management (Ying et al., 2012).

At that point is worth to mention the integration of threedimensional data in X3D format with other data labelled in XML, such as temporal data (Hetherington et al., 2006).

The concurrence of geographic and alphanumeric data involves, for software tools, the ability to store, manage and process them simultaneously (Karki et al., 2010). This practically forces to manage complex scenarios from a database manager that is capable to work with both types of information together. It usually implies to join different computational technologies.

Due to the numerous possibilities that may arise regarding the information needs of these projects, data models are often developed based on the Levels of Details (LoD). The concept of LoD could be summarized as how much detail is included in the model element (BIMForum, 2013), and should not be confused with spatial resolution (interrelated term). For example, a building includes constructive elements, rooms and other objects (walls, doors, windows, floor surfaces, ceilings), depending on the degree of detail. Moreover, the accuracy of the shapes of these objects can be described and classified using different codes; e.g. the German geo-information system ATKIS (Authoritative Topographic-Cartographic Information System) based on standardized data models for an object-based description of the Earth's surface (AdV, 2013).

The precision code and $\mathrm{LoD}$ allows us to overcome the classical management of geographic information on scales. This way when the client requests a piece of land to a given $\mathrm{LoD}$, the database manager can filter data through code accuracy to provide the information requested.

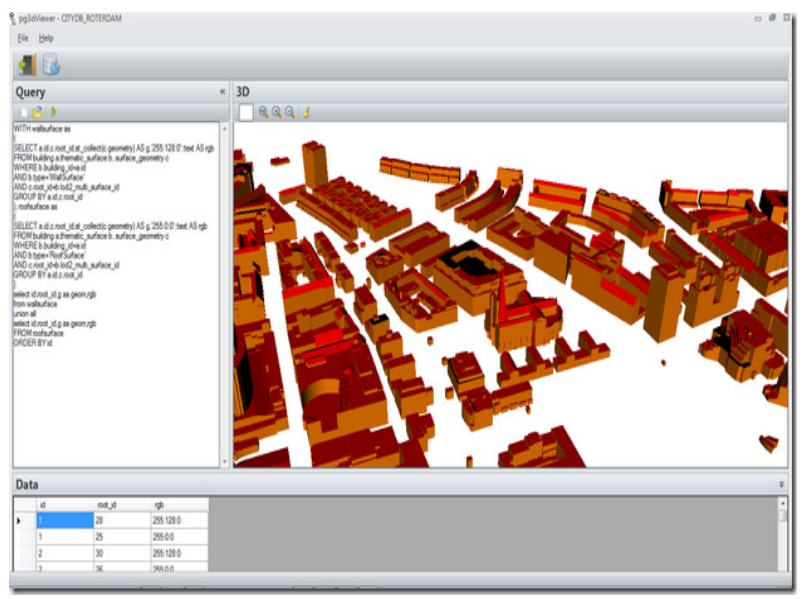

Figure 6. PostGIS 3D viewer.

However, a further step when publishing or sharing such models is necessary. In most cases these direct connection to three-dimensional databases is not considered because of the high transactional cost involved and because most of the 3D viewers have no direct connection to these databases.

In client / server structures, it is impossible to have direct connection among all possible exchange information formats. The communication both thin clients (web browsers) as fat clients (GIS software), works in an encrypted file using a known standard (Figure 7). This situation has already happened in the $2 \mathrm{D}$ world, when trying to publish geographic information, since when a user connects to a WMS service, the client receives from the server an image in a standardized format (Jpeg, Tiff, etc.). For Web Feature Service (WFS) both geometries and associated data is received in standardized file format as GML (Himsolt, 2010), regardless of the format in which the geographical information is stored on the server.

Currently, one of the strategies most commonly used is the combination of databases and files in formats that can incorporate data and $3 \mathrm{D}$ geometries. It is very common to go from database to any standardized formats that are widely used by most $3 \mathrm{D}$ viewers, such as KML/KMZ or CityGML (OGC, 2012). 


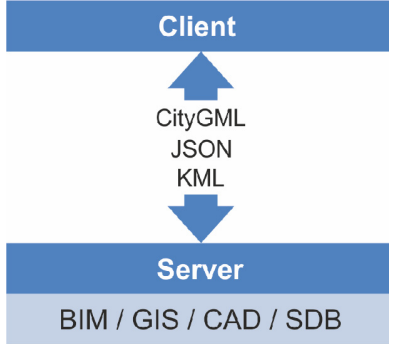

Figure 7. Client/Server architecture for 3D information interchange.

In this context major advances are occurring for the exchange of 3D spatial information. And it will be the core of the next point.

\section{PUBLISHING 3D INFORMATION. OGC STANDARDS}

It is a well known fact that publish and disseminate information through the Internet is on the basis of a successful policy for geographic information. In this sense, some innovative and lively ways to publish 3D models are being developed currently (Figure 8).

Today we found a situation where most of 3D modeling software has its own viewers which can be desktop plugins or web based. Although import and export functions are able to perform communication between systems, this way is not the most suitable. Therefore a new strategy is required according to the criteria of interoperability

To achieve this goal is very important to define a data model which provides a common framework between different modeling and 3D visualization tools. There are different data models that meet this assumption, such as KML, CityGML, LandXML or IndoorGML. All of them are based on XLM and have already become standards for the OGC.

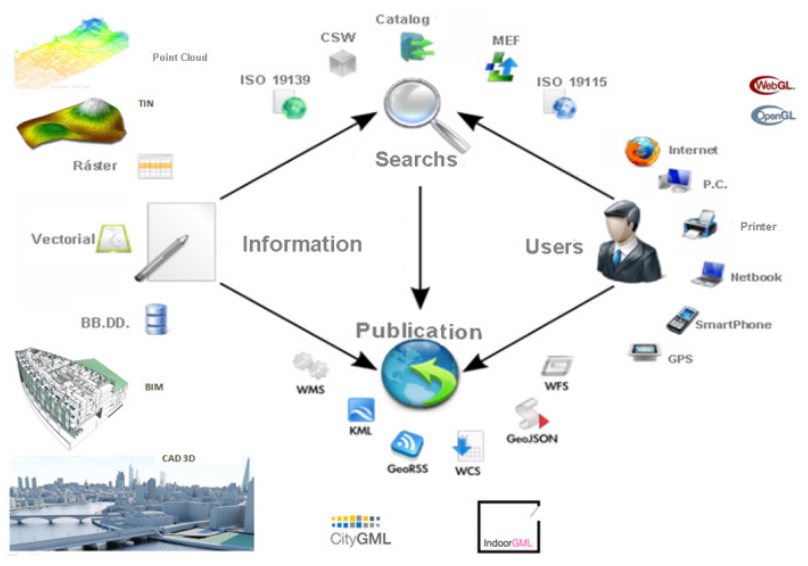

Figure 8. Publishing of 3D models with interoperability.

The KML model has practically become a standard due to its popularity and use. It is currently in its 2.2.0 development version. It allows publishing in the same file many different data such as vector, image, text, links, etc. This format also includes navigation capabilities along different points controlling the speed. As a consequence KML could be considered as a simple and well-structured data model.
CityGML was designed to store and exchange virtual 3D city models. It is another standard for the exchange of spatial data developed by the OGC and ISO TC211. Its main objective is to become the reference format for the exchange of basic entities, attributes and relationships of city models.

In spite of files become more memory demanding than in KML data model it has a greater capacity to store alphanumeric information.

It is important to highlight that CityGML is able to work with the LoD concept. For this purpose five different levels of detail are covered (Figure 9) according to the Open Geospatial Consortium (OGC, 2012):

- LoD0: terrain-only

- LoD1: extruded polygons upon a terrain

- LoD2: LoD1 with roof structures and roof textures

- LoD3: LoD2 with external architectural details

- LoD4: LoD3 with internal rooms (LoD4)

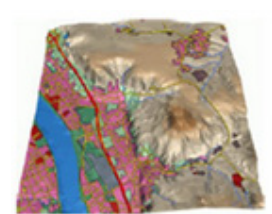

LOD0

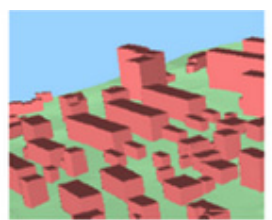

LOD1

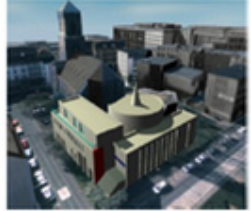

LOD2
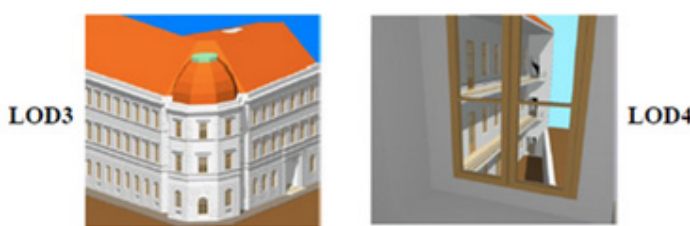

Figure 9. Different LoD in CityGML. Figure courtesy of OGC.

LandXML is another standard based on XML. It is the oldest of all and was developed for the exchange of civil engineering projects, with its associated data and measurements.

Finally IndoorGML (Nagel et al., 2010) is a topological model that has recently become a standard adopted by the OGC. Its primary mission is to serve as a method of transferring information on indoor location. The initiative to create IndoorGML arises from East Asian countries, showing great interest in developing this type of location technologies and indoor navigation due to the high growth of technologies such as RFID (Radio Frequency IDentification) and an enormous development of their telecommunications networks.

IndoorGML provides a detailed description and topologically structured navigable spaces of a building (Figure 10), but also allows easy integration of external navigation systems. These properties make this data model a good alternative for risk prevention projects, emergencies, security, etc. 


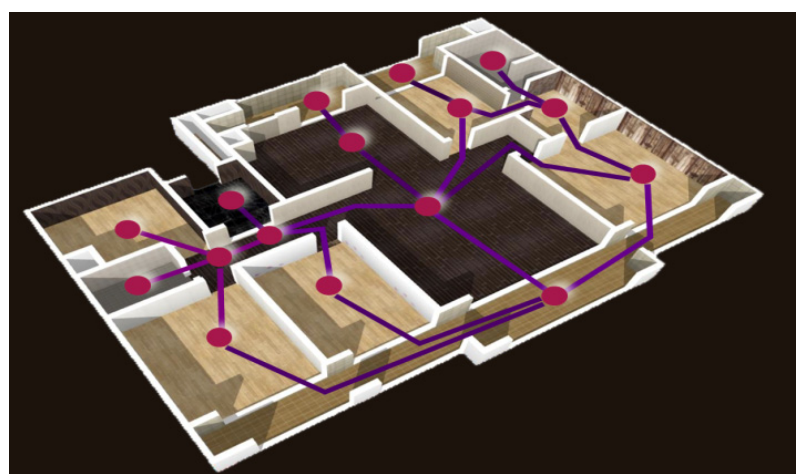

Figure 10. Model of IndoorGML schema. Figure courtesy of OGC.

As shown, each model has different properties even though all are based on interoperability, universality, accessibility and exchange criteria. The idea is that you should be able to access 3D models for the purpose needed at the time, with any computer, in any part of the world, at any moment of the day and independently of the software you are working.

There are many desktop software capable of manage some kind of referred model and visualize it in 3D. However, the challenge is to publish the models directly on the Web, i.e. to work from a web browser with $3 \mathrm{D}$ models without having to install anything. Current technologies such as standard formats, libraries and plugins for $3 \mathrm{D}$ visualization are part of the socalled 3D Web. The most significant are (Prieto et al., 2012):

- WebGL: a cross-platform open standard API for low 3D graphics. It can be accessed as a DOM interface.

- X3DOM: experimental open source framework for integrating HTML5 specification and 3D content. It is based on Javascript and WebGL.

- HTML5: the canvas in which to embed 3D graphics. X3D thus include HTML objects.

These three technologies allow to publish on the corresponding data model files on X3D format from W3DS service. The aim is to watch the $3 \mathrm{D}$ information present in models, in different Web applications.

Three-dimensional models on the Web requires consideration of the spatial data and information associated with it (Rodrigues et al., 2013). So it is necessary to develop a protocol for transactions both spatial data and alphanumeric data. The way to do this is shown in the following figure (Figure 11)

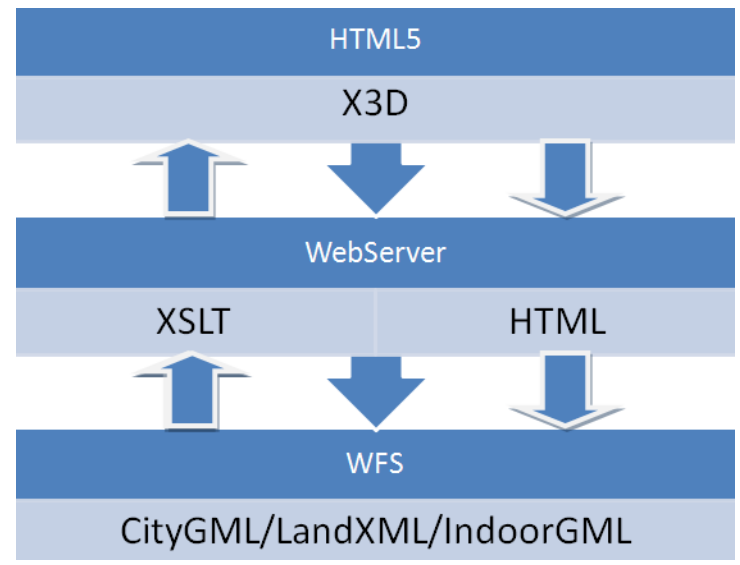

Figure 11. Transactions of geographical and alphanumeric data schema.

\section{CONCLUSIONS}

Throughout this paper complex scenarios that we can find when modelling different types of three-dimensional elements were studied, from elements of small extent, through the modeling of cities and even the rendering of large areas.

It has been shown the different types of alternatives for 3D modeling cities, which has been compared in order to assess their functionalities. This paper has attempted to analyze the different situations that we can face when modeling 3D geographic information, weighing up alternatives and showing solutions that are being discussed right now. The importance to link associated information to graphic $3 \mathrm{~d}$ models has been highlighted too.

Finally we address the issue of web based 3D models due to the importance of publishing and disseminating geographical information policies, according to the interoperability criteria.

The virtual modeling faces many challenges ahead, not only in the city modeling, but also in the complex architectures and cultural heritage, with their inherent difficulties.

As discussed, the BIM and Geomatics, as a researching areas, have obvious synergies that feed themselves, demanding common strategies and policies, and predicting interesting advances in the coming years.

\section{REFERENCES}

\section{References from Books:}

Dellepiane, M., Callieri, M., Corsini, M., Scopigno, R., 2011. Using digital 3D models for study and restoration of cultural heritage artifacts. Digital imaging for cultural heritage. CRC Press, New York, USA, pp. 39-70.

Pinto, N. N., Tenedório, J. A., Antunes, A. P., Cladera, J. R., 2013. Technologies for urban and spatial planning: Virtual cities and territories. IGI Global, Hershey, USA.

\section{References from Journals:}

Elberink, S. O., Stoter, J., Ledoux, H., Commandeur, T., 2013. Generation and dissemination of a national virtual 3D city and landscape model for the Netherlands. Photogrammetric engineering \& remote sensing, 79(2), pp. 147-158.

Hetherington, R., Farrimond, B., Presland, S., 2006.Information rich temporal virtual models using X3D. Computers \& graphics, 30(2), pp. 287-298.

Nex, F. Remondino, F., 2014. UAV for 3D mapping applications: a review. Applied geomatics, 6(1), pp. 1-15.

Niemeyer, J., Rottensteiner, F., Soergel, U., 2014. Contextual classification of Lidar data and building object detection in urban areas. ISPRS journal of photogrammetry and remote sensing, 87, pp. 152-165.

Prieto, I., Egusquiza, A., Delgado, F. J., Martínez, R., 2012. CityGML como modelo de datos para la representación, intercambio y visualización de información sobre el patrimonio arquitectónico. Virtual archaeology review, 3(5), pp. 48-52.

Puente, I., González-Jorge, H., Martínez-Sánchez, J., Arias, P., 2013. Review of mobile mapping and surveying technologies. Measurement, 46(7), pp. 2127-2145. 
Volk, R., Stengel, J., Schultmann, F., 2014. Building information modeling (BIM) for existing buildings - Literature review and future needs. Automation in construction, 38, pp. 109-127.

Yin, L., Shiode, N., 2014. 3D spatial-temporal GIS modeling of urban environments to support design and planning processes. Journal of urbanism: international research on placemaking and urban sustainability, 7(2), pp. 152-169.

Zlatanova, S., Rahman, A. A., Shi, W., 2004. Topological models and frameworks for 3D spatial objects. Computers \& geosciences, 30(4), pp. 419-428.

\section{References from Other Literature:}

Amirian, P., Basiri, A., Winstanley, A., 2014. Evaluation of data management systems for geospatial big data. Lecture notes in computer science, 8583, pp. 678-690.

Basanow, J., Neis, P., Neubauer, S., Schilling, A., Zipf, A., 2008. Towards 3D spatial data infrastructures (3D-SDI) based on open standards-experiences, results and future issues. Advances in 3D geoinformation systems, pp. 65-86.

Benitez, S., Baillard, C., 2009. Automated selection of terrestrial images from sequences for the texture mapping of 3D city models. In: The international archives of the photogrammetry, remote sensing and spatial information sciences, Rostock, Germany, Vol. XXXVIII, Part 3/W4, pp. 97 102.

Calle, M. D. L., Gómez-Deck, D., Olaya Ferrero, V., 2010. Desarrollo personalizado de aplicaciones SIG 3D. In: IV jornadas SIG libre, Girona, Spain.

Curtis, E., 2008. Serving CityGML via web feature services in the OGC web services-phase 4 testbed. Advances in $3 D$ geoinformation systems, pp. 331-340.

Engel, J., Pasewaldt, S., Trapp, M., Dollner, J., 2012. An immersive visualization system for virtual $3 \mathrm{D}$ city models. In: 20th international conference on geoinformatics, pp. 1-7.

Haala, N., Peter, M., Kremer, J., Hunter, G., 2008. Mobile Lidar mapping for 3D point cloud collection in urban areas - A performance test. In: The international archives of the photogrammetry, remote sensing and spatial information sciences, Rostock, Germany, Vol. XXXVII, Part B5, pp. 11191124.

Herreruela, J., 2012. Deploying 3D city models for urban and metropolitan planning. In: Oracle spatial user conference, Washington, DC, USA.

Himsolt, M., 2010. GML: A portable graph file format. Technical report, Universität Passau.

Karki, S., Thompson, R., McDougall, K., 2010. Data validation in $3 \mathrm{D}$ cadastre. Developments in $3 D$ geo-information sciences, pp. 92-122.

Nagel, C., Becker B., Kaden, R., Li, K.J., Lee, J., Kolbe, T. H., 2010. Requirements and space-event modeling for indoor navigation, OGC 10-191r.

Rebecca, O. C., Gold, C., Kidner, D., 2008. 3D City modelling from LiDAR Data. Advances in $3 D$ geoinformation systems, pp. 161-175.

Rodrigues, J. I., Figueiredo, M. J., Costa, C. P., 2013. Web3DGIS for city models with CityGML and X3D. In: 17th international conference information visualisation, pp. 384388 .

Scianna, A., Ammoscato, A., 2010. 3D GIS data model using open source software. In: The international archives of the photogrammetry, remote sensing and spatial information sciences, Melbourne, Australia, Vol. XXXVIII, part 4-8-2-W9, pp. $120-125$.

Slingsby, A., Raper, J., 2008. Navigable space in 3D city models for pedestrians. Advances in $3 D$ geoinformation systems, pp. 49-64.

Suleiman, W., Joliveau, T., Favier, E., 2011. 3D urban visibility analysis with vector GIS data. In: 19th annual GIS research $U K$, Portsmouth, UK.

Van Oosterom, P., Stoter, J., \& Lemmen, C., 2005. Modelling of 3D cadastral systems. In: 28th cadastral seminar, Busan, Korea, pp. 594-606.

Van Oosterom, P., Stoter, J., Ploeger, H., Thompson, R., Karki, S., 2011. World-wide inventory of the status of 3D cadastres in 2010 and expectations for 2014. In: FIG working week, Marrakechh, Morocco, pp. 18-22.

Varela García, F. A., Hernández Ibáñez, L. A., Taibo Pena, J., Seoane, A., 2007. Ampliación de las capacidades de visualización de un SIG libre mediante la comunicación con un navegador 3D. In: I jornadas de SIG libre, Girona, Spain.

Walenciak, G., Stollberg, B., Neubauer, S., Zipf, A., 2009. Extending spatial data infrastructures $3 \mathrm{D}$ by geoprocessing functionality-3D simulations in disaster management and environmental research. In: International conference on advanced geographic information systems \& web services, pp. 40-44.

Ying, S., Guo, R., Li, L., He, B., 2012. Application of 3D GIS to $3 \mathrm{D}$ cadastre in urban environment. 3rd international workshop on $3 D$ cadastres: Developments and practices, Shenzhen, China.

References from Websites (Last accessed on 2015, Jan. 24):

AdV. 2013. Digital basic-landscape model (Basic-DLM). http://www.adv-

online.de/icc/exteng/broker.jsp?uMen=84d3021b-2c20-c221d5ad-8f138a438ad1.

BIMForum, 2013. Level of development specification. http://bimforum.org/wp-content/uploads/2013/08/2013-LODSpecification.pdf.

Cityzenith, 2013. 5D smart city. http://www.cityzenith.com/ city.html.

GeoMind, 2013. http://www.geomind.it/dbmap-3d/.

OGC, 2012. OpenGIS ${ }^{\circledR}$ city geography markup language (CityGML) encoding standard, version 2.0 . http://www.opengeospatial.org/standards/citygml.

VirtuelCity, 2010. http://www.virtuelcity.com/en/3dengineering. 